\title{
Moving targets: how the rapidly changing tobacco and nicotine landscape creates advertising and promotion policy challenges
}

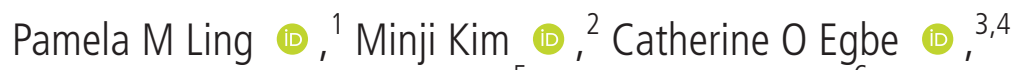 \\ Roengrudee Patanavanich (10, ${ }^{5}$ Mariana Pinho (1) ${ }^{6}$ Yogi Hendlin (i) ${ }^{7}$
}

${ }^{1}$ Department of Medicine and Center for Tobacco Control Research and Education, University of California San Francisco, San Francisco, California, USA

${ }^{2}$ Department of Health Promotion, Education, and Behavior, University of South Carolina Arnold School of

Public Health, Columbia, South Carolina, USA

${ }^{3}$ Alcohol, Tobacco and Other Drug Research Unit, South African Medical Research

Council, Pretoria, Gauteng, South Africa

${ }^{4}$ Department of Public Health, Sefako Makgatho Health

Sciences University, Pretoria, Gauteng, South Africa

${ }^{5}$ Department of Community Medicine, Mahidol University Faculty of Medicine

Ramathibodi Hospital, Bangkok, Thailand

${ }^{6}$ Tobacco Control Project, ACT Health Promotion (Brazil), Rio de Janeiro, Brazil

${ }^{7}$ Erasmus School of Philosophy, Erasmus University Rotterdam, Rotterdam, The Netherlands

\section{Correspondence to}

Dr Pamela M Ling, Department of Medicine and Center for Tobacco Control Research and Education, University of California San Francisco, San Francisco, CA 94143-1390, USA; Pamela.Ling@ucsf.edu

Received 12 October 2021 Accepted 1 December 2021

Check for updates

(c) Author(s) (or their employer(s)) 2022. No commercial re-use. See rights and permissions. Published by BMJ.

To cite: Ling PM, Kim M, Egbe CO, et al. Tob Control 2022:31:222-228.

\section{ABSTRACT}

Tobacco, nicotine and related products have and continue to change rapidly, creating new challenges for policies regulating their advertising, promotion, sponsorship and sales. This paper reviews recent commercial product offerings and the regulatory challenges associated with them. This includes electronic nicotine delivery systems, electronic non-nicotine delivery systems, personal vaporisers, heated tobacco products, nicotine salts, tobacco-free nicotine products, other nicotine products resembling nicotine replacement therapies, and various vitamin and cannabis products that share delivery devices or marketing channels with tobacco products. There is substantial variation in the availability of these tobacco, nicotine, vaporised, and related products globally, and policies regulating these products also vary substantially between countries. Many of these products avoid regulation by exploiting loopholes in the definition of tobacco or nicotine products, or by occupying a regulatory grey area where authority is unclear. These challenges will increase as the tobacco industry continues to diversify its product portfolio, and weaponises 'tobacco harm reduction' rhetoric to undermine policies limiting marketing, promotion and taxation of tobacco, nicotine and related products. Tobacco control policy often lags behind the evolution of the industry, which may continue to sell these products for years while regulations are established, refined or enforced. Policies that anticipate commercial tobacco, nicotine and related product and marketing changes and that are broad enough to cover these product developments are needed.

\section{INTRODUCTION}

The landscape of commercial tobacco, nicotine and related products has changed substantially over the past 30 years, accelerating in the past decade. While cigarettes continue to be the dominant form of tobacco use, the number, variety and uptake of more recently developed products are increasing, ${ }^{1}$ particularly among youth. ${ }^{2}$ Youth uptake of nicotine and other vaporised products may sustain nicotine addiction or lead to smoking and other substance initiation. ${ }^{3-5}$ An enormous number and variety of electronic nicotine delivery products are in the market, with nearly 16000 flavours available, ${ }^{6}$ and global sales rising to US\$15 billion in $2019 .{ }^{17}$ Heated tobacco products (HTPs) were also available in over 50 markets worldwide in $2020 .^{7}$ The continued introduction of such products creates challenges for marketing policy and regulation. ${ }^{89}$
This paper reviews examples of commercial tobacco, nicotine, and other related products introduced or marketed more aggressively in the past decade and highlights features in their advertising, promotion, sponsorship and sales that create challenges for tobacco control policy, in order to identify evolving needs for effective policy addressing these products' marketing. While examples herein highlight marketing activities or challenges faced in specific countries, they reflect broader issues likely to be found elsewhere in the world.

\section{ELECTRONIC NICOTINE DELIVERY SYSTEMS}

The 2021 WHO report on the global tobacco epidemic included a call to address 'new and emerging tobacco products'. ${ }^{1}$ Electronic nicotine delivery systems (ENDS) and electronic nonnicotine delivery systems (ENNDS) ${ }^{10} 11$ are subject to different regulatory policies around the world: as of 2020, ENDS/ENNDS sales are banned in 32 countries, and advertising and promotion of ENDS/ ENNDS is prohibited completely or partially in 75 countries. ${ }^{112}$ Many countries limit age of purchase, require licensing as medicines, limit public use, or limit nicotine concentrations, ingredients or flavours. ${ }^{13}$ The policies and regulations on combustible tobacco products are reviewed elsewhere in this issue. ${ }^{14}$ The introduction of new ENDS/ENNDS products and features has typically been faster than regulations can be developed, and the market and advertising continue to evolve rapidly. ${ }^{6} 15$ Variability in size, efficiency, power, heating materials and liquids creates challenges for regulation. For example, 'pod vape'-style ENDS like the JUUL-branded devices typically have high levels of nicotine. Following European Union 2016 regulations limiting nicotine content to $20 \mathrm{mg} / \mathrm{mL}$ in ENDS liquids, ${ }^{16}$ in 2019 JUUL released products that increased nicotine delivery by over $50 \%$ by changing their wick designs rather than increasing nicotine content in the liquid. ${ }^{17}$ In addition to nicotine, the solvents and flavours present in the liquids in ENDS/ENNDS may have toxicity warranting regulation. ${ }^{18-20}$ Most flavours in ENDS/ENNDS are food additives that were not safety tested for heating and inhalation. ${ }^{21}{ }^{22}$ More recently, while some ENDS marketing applications have been denied in the USA, ${ }^{23}$ millions of ENDS/ENNDS products are already being sold, ${ }^{24}$ and it is unknown how to efficiently or effectively stem the tide.

Enforcement of regulations and advertising control policies is a global challenge. For example, 
although sales and imports of all ENDS products are banned in Thailand, ${ }^{25}$ they are sold illegally via online platforms. ${ }^{26-28}$ The same is true in Brazil, where marketing, advertising and importation of ENDS are not allowed, but they are sold illegally at vape shops, tobacco stores, on the internet and by using delivery apps. ${ }^{29} 30$ In South Africa, ENDS are to be sold only by prescription, but they are widely advertised as smoking cessation products and sold without prescription. ${ }^{31}$ Policies narrowly applied to specific types of ENDS are easily circumvented by making small modifications; in the USA when the Food and Drug Administration (FDA) announced it would prioritise enforcement of flavour bans in reusable pod ENDS, disposable ENDS exploited this loophole, and high school student use of disposable ENDS increased from $2.4 \%$ in 2019 to $26.5 \%$ in $2020 .^{32}$ Similarly, since the 2017 Tobacco Business Act in South Korea defined tobacco as a product 'manufactured in a state suitable for smoking, sucking, inhaling steam, chewing or smelling, by using tobacco leaves as all or any part of the raw materials, ${ }^{33}$ some ENDS manufacturers introduced liquids for inhalation with nicotine derived from the stem or root of the tobacco plant to circumvent these regulations. ENNDS products with added vitamins, nutrients and herbal supplements may be perceived as healthy without scientific evidence of health benefit, ${ }^{34}$ and it may not be clear if they can be regulated as tobacco products. Indeed, vitamin ENNDS may be promoted as nicotine free to imply health benefits.

\section{HEATED TOBACCO PRODUCTS}

The popularity of ENDS/ENNDS opened market opportunities for HTPs, which contain tobacco heated to temperatures short of combustion to produce tobacco smoke for inhalation. ${ }^{35}$ Previous heated cigarette products failed due to poor acceptability and inability to deliver on promises of eliminating secondhand smoke, ${ }^{36}$ but over time devices have become smaller, cheaper and more convenient, and consumers using ENDS are more likely to try HTPs. ${ }^{37} 38$ Newer generations of HTPs launched in Japan in $2014^{39}$; in 2021 Japan had the highest number of HTP users in the world ${ }^{40}$ with Philip Morris International's (PMI) IQOS leading the market. ${ }^{41}{ }^{42}$ HTPs are more likely to be used by younger adults ${ }^{43}$ and people with higher income. ${ }^{44}$ There is variability in policies regulating HTPs: some countries completely ban sales or import, while others include HTPs under tobacco regulations. ${ }^{45}$ In South Africa, HTPs are subject to the same regulations as cigarettes, but since many HTPs resemble ENDS, which are not regulated as tobacco products, regulating HTP is challenging. In Thailand where HTPs are banned, ${ }^{46}$ the products are sold illegally. ${ }^{267}$ In Japan and Korea, there are more strict limitations on ENDS and fewer restrictions on HTP advertising than cigarettes, which has resulted in aggressive promotion of HTPs which now occupy $14.3 \%$ of the total tobacco market in Korea and 30\% in Japan. ${ }^{48}$ In 2020 in Japan, 53\% of tobacco advertisements in newspapers and 94\% of tobacco advertisements in magazines promoted HTPs. ${ }^{49}$ In Korea, HTP devices were considered to be electronics rather than tobacco products ${ }^{50}$ so HTPs have been advertised with lifestyle appeals, including a 2019 British American Tobacco (BAT) social media campaign featuring hip hop musicians popular among youth. ${ }^{50} 51$ The music video avoided age restrictions because it included images of the heating devices but not the tobacco pods, accruing more than a million views. ${ }^{51}$ In Germany, the 'neo glo' (BAT) HTP features a 'boost' feature which gives an extra strong hit of nicotine, and an 'ergonomic' and colourful closed system design. ${ }^{52}$ BAT's HTPs have 'gained share in all key markets' in 2021. ${ }^{53}$
Some tobacco companies aimed to promote HTP products as reduced harm. ${ }^{36}$ The US FDA authorised PMI to make an 'exposure modification' but not a 'risk modification' claim for IQOS in $2020 .{ }^{54}$ While the FDA regulates only US tobacco products, many other countries rely on FDA for guidance on how to regulate recently developed products. ${ }^{55}$ The FDA exposure modification authorisation was used to promote IQOS sales as a safer tobacco product in other countries. ${ }^{56}$ In Thailand, ENDS advocates advertised that the FDA had found IQOS 'appropriate for the protection of the public health'. ${ }^{25}$ In Korea, where relative risk claims are allowed as long as the claim does not deceive customers, IQOS was promoted, using a 'Science Machine' resembling a now defunct smoking machine ${ }^{57}$ that collected cigarette smoke and HTP smoke on filter paper to show that HTPs produced fewer residuals than a cigarette. ${ }^{585}$ Smoking machine yields were intentionally misrepresented by tobacco companies in the past to mislead the public by implying low-tar cigarettes were healthier. ${ }^{57}$ In Japan, reduced risk claims ${ }^{60}$ exceptions for HTPs in smoke-free policies, and social acceptability all contribute to HTP popularity. ${ }^{61}$ In Canada, HTP devices and tobacco sticks were sold without graphic warning labels. ${ }^{62}$

PMI and ENDS advocacy groups used reduced risk messaging on websites and social media to pressure the government to lift the ENDS ban in Thailand. ${ }^{25}$ Similarly, in South Africa, tobacco harm reduction claims were used by ENDS manufactures, to challenge efforts to regulate ENDS, ${ }^{563}$ and in Brazil the National Regulatory Agency has been pressured by ENDS advocates and PMI to lift the ban on ENDS and HTPs using harm reduction arguments in public comment ${ }^{64}$ and on social media. ${ }^{6566}$

\section{PAIRING TOBACCO PRODUCTS WITH OTHER CONSUMER GOODS}

New ENDS/ENNDS features will continue to emerge with unclear regulatory authority. For example, products with personal electronic features, such as connections to apps, ${ }^{67}$ voice-controlled cloud-based technology like Amazon's Alexa, ${ }^{68}$ or Bluetooth speakers, ${ }^{69}$ have appeared in US markets. Bluetooth and smartphone apps that connect to vape devices have been proposed for entertainment and age enforcement (eg, detection of devices in schools) ${ }^{70-72}$; these features may also allow manufacturers to track and monitor users passively. Korean IQOS' Bluetooth technology can record battery level and usage, and a third-party app uses the information to track number of tobacco sticks smoked per day, as well as the days and times IQOS is used most. ${ }^{73}$ JUUL has produced devices in the UK and Canada with Bluetooth connected to a phone app to allow tracking of vape consumption claiming utility to prevent youth use, ${ }^{70} 7174$ and JUUL continued to file patent applications for 'smart' ENDS in $2020 .^{75}$ HTPs that resemble personal electronic devices may appear to be safer due to perceived technological advancement or because they share the familiar ubiquity of electronic devices in everyday life. Differentiation from cigarettes and association with personal electronics may be advantageous in markets where cigarette smoking is denormalised. ${ }^{76}$ Other accessories such as lanyards and holders share a 'friendly familiarity' with other consumer products and may not be included in definitions of tobacco products, making them difficult to regulate. ENDS/ ENNDS that resemble speakers, watches or lipsticks may be difficult to recognise, creating a challenge for policy enforcement.

In addition to electronics, flavoured 'add-ons' pose a regulatory challenge. Cigarettes with flavoured capsules are popular in Europe, Africa, Latin America and Asia, and flavoured cigarette bans may not include capsules. ${ }^{77}$ In Brazil, while tobacco 


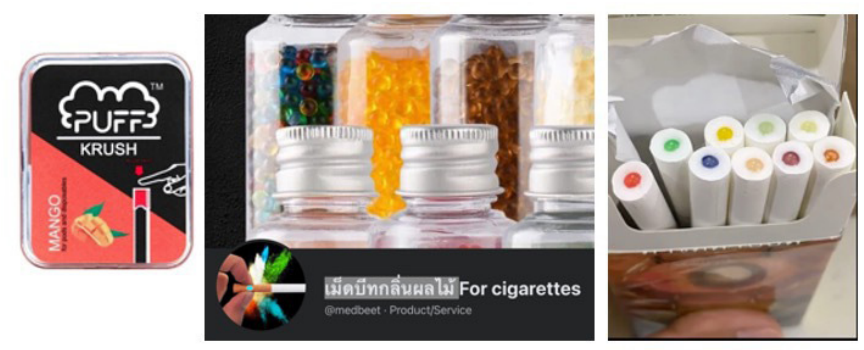

Figure 1 Flavoured 'add on' products. 'Puff Krush' flavoured silicon caps for pod vape devices in the USA (left), and crushable flavour beads sold for insertion into cigarettes in Thailand (right).

additives are prohibited, due to numerous lawsuits, the regulatory measure is still not fully implemented, and flavoured capsules continue to be sold. There is pressure to allow flavoured additives in ENDS as influencers claim the flavours are essential for smoking cessation. As FDA began to enforce eliminating some flavoured ENDS, 'Puff Krush' silicone caps containing flavour capsules designed to fit on pod vape devices appeared in the USA (figure 1 ) $^{78}$; separate flavour cards and menthol drops were sold in Canada following the menthol ban. ${ }^{79}$ In Thailand, crushable flavour beads are sold for insertion in cigarettes (figure 1), but pose a regulatory challenge as they are sold separately from tobacco products and also promoted for other uses, such as adding to COVID-19 pandemic face masks to improve bad breath. ${ }^{80-82}$

\section{NICOTINE SALTS}

Nicotine salt liquids (also called 'Salt Nic') with organic acids added to enhance appeal and sensory experience have become widely used in ENDS. ${ }^{83}$ Nicotine salt liquids dramatically increased nicotine content and efficiency of nicotine delivery. ${ }^{84} \mathrm{In}$ addition to higher nicotine content, US products are available in large sizes with $3000-4000$ puffs, $8-12$ mL liquid. ${ }^{85}{ }^{86}$ Nicotine salts are also offered in nicotine pouches, which resemble and are used similarly to oral tobacco products like Swedish snus, but instead of tobacco leaf contain nicotine, flavourants and binders in a porous pouch. ${ }^{87}$ Nicotine salts are perceived by consumers to be an innovation, an improvement, better tasting and better quality. ${ }^{168388}$ While high-nicotine content may encourage users to switch away from cigarettes or to consume less liquid thus decreasing exposure to toxicants, ${ }^{89}$ it may also facilitate youth nicotine addiction. ${ }^{84}$ The marketing of these products drives who adopts the product and whether the use pattern is beneficial for population health. In the USA, ENDS with nicotine salts became rapidly popular among youth, first with marketing of JUUL brand devices, ${ }^{90}$ and continued marketing and promotion of disposables such as Puff Bar. ${ }^{91}$ Youth use of ENDS led to the net result of more population harm than benefit. ${ }^{92}$

\section{NICOTINE GUM, LOZENGE AND POUCH PRODUCTS}

In recent years, some tobacco companies have started to sell nicotine gum, lozenges and pouches without claims to be nicotine replacement therapies (NRTs). ${ }^{93}$ Nicotine gum and pouches sold in convenience stores may attract consumers to use nicotine for purposes other than smoking cessation. The Lucy brand in the USA sells nicotine gum (pomegranate, spearmint) and nicotine lozenges (cherry ice, citrus, mint), and pouches (spearmint, mango, cool cider) in flavours more appealing than approved NRTs. The Lucy website states its lozenge products are FDA approved for smoking cessation, while the gum is not; the website claims the gum contains a different 'unique nicotine resinate' with greater bioavailability. ${ }^{94}$ Nicotine salt pouch products (eg, On, Dryft, Zyn) were introduced in the USA in 2016, followed by Rogue in 2018, and sales increased exponentially since their introduction. ${ }^{87}$ Nicotine pouches are made or distributed by the major tobacco companies in the USA and these products are not approved for smoking cessation; they feature a wider variety of flavours (eg, mango, cinnamon, honey lemon, black cherry, mint) and higher levels of nicotine than NRTs. ${ }^{87}$ In addition, products are converging under the same brand names. RJR Vapor's nicotine lozenge (Revel) was subsequently rebranded with its pouch brand name, Velo. ${ }^{95}$ RJR's parent company, BAT, announced in 2020 that it would be building a first of its kind factory in Kenya to manufacture nicotine pouches, ${ }^{96}$ and planned to expand sales of Velo nicotine pouches in Indonesia in 2021. ${ }^{97}$ Rogue nicotine includes pouches, gum and lozenges under a single brand..$^{98}$ Consolidating different nicotine products under the same brand name may confuse consumers and give the unapproved products the appearance of FDA approval.

\section{'TOBACCO-FREE NICOTINE': SYNTHETIC NICOTINE}

Some nicotine pouches, gum and ENDS claim they contain synthetic nicotine, exploiting another regulatory gap in the USA, falling outside of the definition of tobacco product by the Federal Food Drug and Cosmetic's Act. ${ }^{99}$ After FDA orders to remove their flavoured disposable ENDS from the market in $2020,{ }^{100}$ the makers of Puff Bar announced in early 2021 they were returning to market with 'tobacco-free nicotine' products. ${ }^{101} 102$ In 2021, at least seven new tobacco-free nicotine pouches have been introduced in the US market (2ONE, NIIN, Rush, Fre, FR3SH, Bidi, Lucy). Two brands, 2ONE and NIIN, advertise the use of TFN, a trademarked 'tobacco-free', synthetic nicotine. ${ }^{103}$ Lucy 'kapsel pouches' contain $8 \mathrm{mg}$ of nicotine, double that of other Lucy nicotine products, and claim to contain tobacco-free nicotine unlike Lucy gum and lozenges. An April 2021, search on ENDS retailer websites in the USA found numerous brands of tobacco-free nicotine liquids and disposable pod vaping devices, including both freebase and nicotine salt formulations. ${ }^{104}$ Some products labelled 'tobacco-free nicotine' claim to contain synthetically produced nicotine and others state the nicotine is derived from tobacco but purified. Tobacco plants produce only one of the two chemical enantiomers of nicotine (S-nicotine), while synthetic nicotine is commonly a racemic 50:50 mixture of the two chemical enantiomers (S-nicotine and R-nicotine). ${ }^{105}$ Little is known about the R-nicotine enantiomer because previously human exposure to and intake of R-nicotine was minimal ${ }^{105}$; the substantial presence of R-nicotine in synthetic nicotine products has unknown health impact. ${ }^{9}$

FDA has not made a decision about how it may regulate synthetic nicotine products, ${ }^{101}$ exemplifying how a regulatory agency may lag behind the commercial market, constrained by outdated and narrow legislation. News reports in 2021 stated the Japanese health ministry will regulate tobacco-free nicotine pouches as pharmaceutical products. ${ }^{106}$ In some parts of Africa, BAT's Lyft nicotine pouches are being marketed as 'modern oral nicotine pouch without tobacco', causing regulatory confusion as most tobacco laws do not cover nicotine products. As policies in Africa are reviewed to add ENDS regulations, smokeless nicotine products should also be addressed. Similar to ENDS arguments described above, the tobacco industry pushed back on regulation based on harm reduction claims. ${ }^{107} 108$ Perhaps because they occupy a regulatory loophole, tobacco-free nicotine products are available on the internet from the online retailer Amazon, 


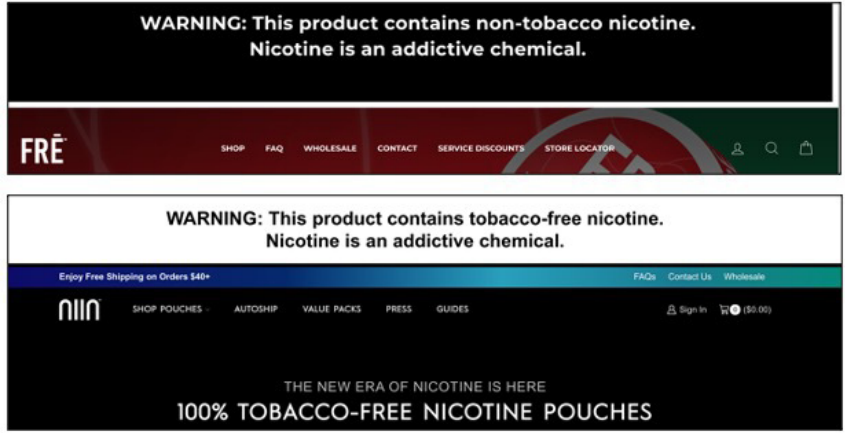

Figure 2 Warning labels appearing on 'tobacco-free nicotine' product websites in the USA with bespoke wording adopting the product's preferred terminology.

which prohibits selling tobacco products and ENDS in the USA. Tobacco-free nicotine products may appear to be regulated; some have invented a warning label which appears similar to the US federal nicotine warning labels, but includes the terms, 'tobacco-free nicotine ${ }^{, 109}$ or 'non-tobacco nicotine'110 (figure 2).

\section{BEYOND NICOTINE}

The use of the term 'pharmaceutical grade' nicotine ${ }^{94}$ to describe recently developed nicotine products and the acquisition of NRTs extends the tobacco industry's embrace of pharmaceuticalisation - producing products that appear like medical therapeutics conferring perceptions of safety. ${ }^{111} \mathrm{~A}$ recent and heavily criticised example of pharmaceuticalisation was PMI's September 2021 takeover of the UK pharmaceutical company Vectura, which produces inhaled medications, an act that prompted protest from the medical community calling it 'deeply disturbing and perverse' that a tobacco company would profit from treatment of the lung diseases caused by its products. ${ }^{112}$ The purchase is consistent with tobacco industry plans to move into cannabis, botanicals and respiratory drug delivery as part of their 'beyond nicotine' strategy to offer a variety of different products that offer consumers 'sensorial enjoyment for different moods and moments'. 113114 In addition to the diversified tobacco industry, a host of other companies are entering the market, producing similar nicotine and vaporised products, including counterfeit products, which raise further regulatory challenges.

\section{TOBACCO AND CANNABIS PRODUCT CONVERGENCE}

Tobacco and cannabis co-use is common, particularly among young people. ${ }^{115-118}$ In the USA, tobacco companies considered entering the cannabis market in the 1960s, but did not do so due to the federal legal status. ${ }^{119}$ Cannabis legalisation in many US states facilitates development of new smoked products. TAAT hemp cigarettes offering a 'nicotine and tobacco-free smoking experience' were introduced in the USA in 2021 by a company led by former PMI executives. ${ }^{120}$ Tobacco and cannabis products may be lumped together for consumers: online 'product reviews' for ENDS/ENNDS, HTPs and cannabis vaporisers frequently appear alongside each other on the same websites. ${ }^{121}$ The popularity of ENDS in the USA was followed by an increase in cannabis vaping among young people, and a proliferation of illicit cannabis vapes that contributed to the outbreak of vapingassociated lung disease. ${ }^{122}$ Vitamin and CBD ENNDS are also likely to be sold in the same space and circumstances as tobacco products but may not be subject to tobacco regulation. Vitamin ENNDS were promoted as a smoking cessation aid in Korea in $2016^{123}$ and were described on the US market in $2018 .{ }^{34}$ CBD products were commonly found in US online vape shops in $2021 .{ }^{124}$

\section{SUMMARY/CONCLUSION}

Recently developed tobacco, nicotine and other vaporised products are continuing to enter markets with aggressive promotion both in high-income countries where cigarette smoking is declining and where consumers can afford expensive new products, as well as in lower and middleincome countries, circumventing policies banning tobacco advertising or ENDS imports. Attention and debate about ENDS/ENNDS and related products may serve to distract or deter policymakers from an appropriate focus on cigarette smoking. The embrace of tobacco harm reduction may allow tobacco and ENDS companies to reposition themselves as partners in public health, which contradicts the Framework Convention on Tobacco Control Article 5.3 and allows the industry to undermine tobacco control. ${ }^{107}$ The tobacco industry continues to use harm reduction arguments to argue against bans on ENDS and recently developed products, taxation of new products, and to push for medical authorisation of nicotine products which might later lead to subsidy of the nicotine products for smoking cessation. ${ }^{64125}$ Finally, as the industry continues to reinvent itself to stay in business, regulatory authorities mostly play 'catch up'. Current strategies which give the industry ample time to market products while they are brought under regulatory frameworks are not helpful for public health. The new product and marketing landscape highlights the need to update measures once considered tobacco control staples (eg, advertising bans, which have to some extent been overtaken and rendered out of date by new online promotional methods) to address marketing of ENDS/ENNDS and other recently developed nicotine and vaporised products. Policies that anticipate changes to products and that ensure regulatory provisions are broad enough to accommodate future potential products will save time, money and lives.

\section{What this paper adds}

- Few studies address the variety of recently introduced tobacco, nicotine, and related products, and how product diversification is used to undermine tobacco control policies.

- This paper details how commercial entities tweak product specifications to circumvent current regulations (and often continue updating their products to stay one step ahead of evolving regulations) to maximize rapid sales that outpace policy development and implementation.

- Escalating numbers of product variants are a worldwide trend in mature tobacco markets, legitimised explicitly or implicitly as reduced harm without supporting scientific evidence, leveraging perceptions of safety and technological advancement to recruit new generations of tobacco and nicotine addicts.

- The tobacco industry deploys harm reduction arguments to circumvent the Framework Convention on Tobacco Control's Article 5.3, to argue against bans on ENDS and recently developed products, pressure against taxation of new products, and to push for medical authorization of nicotine products. 
Contributors PML conceived the paper and led the writing. All authors contributed to the writing, critical revision and final approval of the manuscript.

Funding PML was supported by NIH (grant number U54 HL147127). The other authors have not declared a specific grant for this research from any funding agency in the public, commercial or not-for-profit sectors.

Competing interests None declared.

Patient consent for publication Not required.

Ethics approval This study does not involve human participants.

Provenance and peer review Commissioned; externally peer reviewed.

\section{ORCID iDs}

Pamela M Ling http://orcid.org/0000-0001-6166-9347

Minji Kim http://orcid.org/0000-0002-7715-6826

Catherine 0 Egbe http://orcid.org/0000-0001-5698-6866

Roengrudee Patanavanich http://orcid.org/0000-0001-6277-3912

Mariana Pinho http://orcid.org/0000-0002-8372-9272

Yogi Hendlin http://orcid.org/0000-0002-1714-6132

\section{REFERENCES}

1 World Health Organization. WHO report on the global tobacco epidemic 2021: addressing new and emerging products. Available: https://www.who.int/ publications-detail-redirect/9789240032095 [Accessed 29 Sep 2021].

2 Centers for Disease Control and Prevention. Youth and tobacco use, 2021. Available: https://www.cdc.gov/tobacco/data_statistics/fact_sheets/youth_data/tobacco_use/ index.htm [Accessed 29 Sep 2021].

3 Park E, Livingston JA, Wang W, et al. Adolescent e-cigarette use trajectories and subsequent alcohol and marijuana use. Addict Behav 2020;103:106213.

4 O'Brien D, Long J, Quigley J, et al. Association between electronic cigarette use and tobacco cigarette smoking initiation in adolescents: a systematic review and metaanalysis. BMC Public Health 2021;21:954

5 Yoong SL, Hall A, Turon $\mathrm{H}$, et al. Association between electronic nicotine delivery systems and electronic non-nicotine delivery systems with initiation of tobacco use in individuals aged $<20$ years. A systematic review and meta-analysis. PLoS One 2021;16:e256044

6 Hsu G, Sun JY, Zhu S-H. Evolution of electronic cigarette brands from 2013-2014 to 2016-2017: analysis of brand websites. J Med Internet Res 2018:20:e8550.

7 World Health Organization. WHO Study Group on tobacco product regulation: report on the scientific basis of tobacco product regulation: eighth report of a WHO study group, 2021. Available: https://www.who.int/publications-detail-redirect/ 9789240022720 [Accessed 15 Nov 2021].

8 Tan ASL, Weinreich E. \#PuffBar: how do top videos on TikTok portray Puff Bars? Tob Control. In Press 2021:30:712-3.

9 Jordt S-E. Synthetic nicotine has arrived. Tob Control 2021. doi:10.1136/ tobaccocontrol-2021-056626. [Epub ahead of print: 07 Sep 2021].

10 World Health Organization. Electronic nicotine delivery systems and electronic nonnicotine delivery systems (ENDS/ENNDS) report by WHO, 2016. Available: https:// www.who.int/fctc/cop/cop7/FCTC_COP_7_11_EN.pdf?ua=1 [Accessed 15 Nov 2021]

11 World Health Organization. Progress report on regulatory and market developments on electronic nicotine delivery systems (ENDS) and electronic non-nicotine delivery systems (ENNDS), 2018. Available: https://www.who.int/fctc/cop/sessions/cop8/ FCTC_COP_8_10-EN.pdf?ua=1 [Accessed 15 Nov 2021].

12 Johns Hopkins Institute for Global Tobacco Control. Country laws regulating e-cigarettes, global tobacco control. Available: https://globaltobaccocontrol.org/en/ policy-scan/e-cigarettes/countries? country=81 [Accessed 29 Sep 2021].

13 Kennedy RD, Awopegba A, De León E, et al. Global approaches to regulating electronic cigarettes. Tob Control 2017;26:440-5.

14 Freeman R, Watts C, Astuti PAS. Global tobacco advertising, promotion, and sponsorship regulation: what's old, what's new and where to next? Tob Control 2022:31:98-105

15 Spindle TR, Eissenberg T. Pod mod electronic Cigarettes-An emerging threat to public health. JAMA Netw Open 2018;1:e183518.

16 Mallock N, Trieu HL, Macziol M, et al. Trendy e-cigarettes enter Europe: chemical characterization of JUUL pods and its aerosols. Arch Toxicol 2020;94:1985-94.

17 Karam E, Talih S, Salman R, et al. JUUL 'new technology' pods exhibit greater electrical power and nicotine output than previous devices. Tob Control 2021;20. doi:10.1136/tobaccocontrol-2020-056427. [Epub ahead of print: 07 May 2021].

18 Madison MC, Landers CT, Gu B-H, et al. Electronic cigarettes disrupt lung lipid homeostasis and innate immunity independent of nicotine. J Clin Invest 2019;129:4290-304

19 National Academies of Sciences, Engineering, and Medicine; Health and Medicine Division; Board on Population Health and Public Health Practice. Committee on the Review of the Health Effects of Electronic Nicotine Delivery Systems. In: Eaton DL, Kwan LY, Stratton K, eds. Public health consequences of e-cigarettes. Washington
DC: National Academies Press (US), Toxicology of e-cigarette constituents, 2018. https://www.ncbi.nlm.nih.gov/books/NBK507184/

20 Mulder HA, Patterson JL, Halquist MS, et al. The effect of electronic cigarette user modifications and E-liquid adulteration on the particle size profile of an aerosolized product. Sci Rep 2019;9:10221.

21 Barhdadi S, Rogiers V, Deconinck E, et al. Toxicity assessment of flavour chemicals used in e-cigarettes: current state and future challenges. Arch Toxicol 2021;95:2879-81.

22 Leigh NJ, Lawton RI, Hershberger PA, et al. Flavourings significantly affect inhalation toxicity of aerosol generated from electronic nicotine delivery systems (ENDS). Tob Control 2016;25:iï1-7.

23 FDA Office of the Commissioner. FDA denies marketing applications for about 55,000 flavored e-cigarette products for failing to provide evidence they appropriately protect public health, 2021. Available: https://www.fda.gov/newsevents/press-announcements/fda-denies-marketing-applications-about-55000flavored-e-cigarette-products-failing-provide-evidence [Accessed 29 Sep 2021].

24 FDA Office of the Commissioner. FDA Makes Significant Progress in Science-Based Public Health Application Review, Taking Action on Over $90 \%$ of More Than 6.5 Million 'Deemed' New Tobacco Products Submitted. Available: https://www.fda. gov/news-events/press-announcements/fda-makes-significant-progress-sciencebased-public-health-application-review-taking-action-over-90 [Accessed 29 Sep 2021].

25 Patanavanich R, Glantz S. Successful countering of tobacco industry efforts to overturn Thailand's ends ban. Tob Control 2021;30:e10-19.

26 Phetphum C, Prajongjeep A, Thawatchaijareonying K, et al. Personal and perceptual factors associated with the use of electronic cigarettes among university students in northern Thailand. Tob Induc Dis 2021;19:31.

27 Ashworth C. Man arrested for allegedly running illegal e-cigarette business. Thaiger, 2020. Available: https://thethaiger.com/hot-news/crime/man-arrested-for-allegedlyrunning-illegal-e-cigarette-business [Accessed 26 Nov 2021].

28 sudjudshop. Products - 85W Eleaf iStick Pico 25. Available: https://sudjudshop.co m/\%E0\%B8\%AA\%E0\%B8\%B4\%E0\%B8\%99\%E0\%B8\%84\%E0\%B9\%89\% E0\%B8\%B2 [Accessed 26 Nov 2021].

29 de PinhoM CM, Russo Riva MP, de Souza Cury L. A Promoção de Novos Produtos de Tabaco nas Redes Sociais Luz dA Pandemia. Rev Bras Cancerol 2020;66:e-1108 https://rbc.inca.gov.br/revista/index.php/revista/article/view/1108

30 ACT Promoção da Saúde. Executive Summary - Addiction on Immediate Delivery Dependência- -Pronta-Entrega: 4. Available: https://actbr.org.br/uploads/arquivos/\% 28EN\%29-EXECUTIVE-SUMMARY-Depende\%CC\%82ncia-a\%CC\%80-prontaentrega-\%282\%29.pdf [Accessed 29 Sep 2021].

31 Agaku I, Egbe CO, Ayo-Yusuf O. Associations between electronic cigarette use and quitting behaviours among South African adult smokers. Tob Control 2021 doi:10.1136/tobaccocontrol-2020-056102. [Epub ahead of print: 15 Jan 2021].

32 Wang TW, Gentzke AS, Neff LJ, et al. Disposable E-Cigarette Use among U.S. Youth An Emerging Public Health Challenge. N Eng/ J Med 2021;384:1573-6.

33 Korea Legislative Research Institute. Tobacco business act, 2017. Available: https:// law.go.kr/LSW/LInfoP.do?lsiSeq=195019\&viewCls=engLsInfoR\&urlMode= engLsInfoR\#0000 [Accessed 01 Oct 2021].

34 Basáñez T, Majmundar A, Cruz TB, et al. E-cigarettes Are Being Marketed as "Vitamin Delivery" Devices. Am J Public Health 2019;109:194-6.

35 Auer R, Concha-Lozano N, Jacot-Sadowski I, et al. Heat-Not-Burn tobacco cigarettes: smoke by any other name. JAMA Intern Med 2017;177:1050-2.

36 Ling PM, Glantz SA. Tobacco industry consumer research on socially acceptable cigarettes. Tob Control 2005;14:e3.

37 Berg CJ, Romm KF, Patterson B, et al. Heated tobacco product awareness, use, and perceptions in a sample of young adults in the United States. Nicotine Tob Res 2021:23:1967-71.

38 Miller CR, Sutanto E, Smith DM, et al. Awareness, trial and use of heated tobacco products among adult cigarette smokers and e-cigarette users: findings from the 2018 ITC four country smoking and Vaping survey. Tob Control 2022;31:11-18.

39 Pmi Japan. Available: https://www.pmi.com/markets/japan/en/overview [Accessed 16 Nov 2021].

40 Philip Morris International. Can innovative products like IQOS accelerate the decline of smoking? 2020. Available: https://www.pmi.com/sustainability/case-studies/caninnovative-products-like-iqos-accelerate-the-decline-of-smoking [Accessed 16 Nov 2021].

41 Odani S, Tabuchi T. Prevalence of heated tobacco product use in Japan: the 2020 JASTIS study. Tob Control 2021. doi:10.1136/tobaccocontrol-2020-056257. [Epub ahead of print: 11 Mar 2021].

42 Sutanto E, Miller C, Smith DM, et al. Prevalence, use behaviors, and preferences among users of heated tobacco products: findings from the 2018 ITC Japan survey. Int J Environ Res Public Health 2019;16:E4630.

43 Igarashi A, Aida J, Kusama T, et al. Heated tobacco products have reached younger or more affluent people in Japan. J Epidemiol 2021:31:187-93.

44 Wu YS, Wang MP, Ho SY, et al. Heated tobacco products use in Chinese adults in Hong Kong: a population-based cross-sectional study. Tob Control 2020;29:277-81.

45 Lempert LK, Glantz SA. Heated tobacco product regulation under us law and the FCTC. Tob Control 2018;27:s118-25. 
46 Johns Hopkins Institute for Global Tobacco Control. Heated tobacco regulations June 2020. countries that regulate heated tobacco products June, 2020. Available: https://www.drugsandalcohol.ie/32672/1/heated_tobacco_regulations_jun_2020. pdf [Accessed 26 Nov 2021].

477 sevenvape ร้านขายบุหรี่ไฟฟ้าราคาถูก. มวนบุหรี่ HEETS tobacco sticks for IQOS. Available: https://www.7sevenvape.com/th/product/672527/product-672527 [Accessed 26 Nov 2021]

48 Park H. Domestic e-cigarette market share 15\%. "It will continue to increase." Electronic Times, 2021. Available: https://www.etnews.com/20210120000086? SNS $=00002$ [Accessed 01 Oct 2021].

49 Ichikawa M, Hori A, Inada H, et al. Intensified advertising of heated tobacco products in Japan: an apparent shift in marketing strategy. Tob Control 2021. doi:10.1136/ tobaccocontrol-2021-056615. [Epub ahead of print: 24 May 2021].

50 Kong J, Chu S, Park K, et al. The tobacco industry and electronic cigarette manufacturers enjoy a loophole in the legal definition of tobacco in South Korean law. Tob Control 2021;30:471-2.

51 Yi J, Kim J, Lee S. British American Tobacco's 'Glo Sens' promotion with K-pop. Tob Control 2021:30:594-6.

52 British American Tobacco. Tobacco heating products. Available: https://www. bat-science.com/groupms/sites/BAT_C6ZJDE.nsf/vwPagesWebLive/D0C67AX9? opendocument

53 Reuters. BAT hikes sales growth outlook amid shift to e-cigarettes. Reuters, 2021. Available: https://www.reuters.com/business/retail-consumer/bat-raises-salesgrowth-outlook-smokers-switch-less-harmful-products-2021-06-08/ [Accessed 02 Oct 2021].

54 Office of the Commissioner. FDA Authorizes Marketing of IQOS Tobacco Heating System with 'Reduced Exposure' Information. FDA. Available: https://www.fda.gov/ news-events/press-announcements/fda-authorizes-marketing-iqos-tobacco-heatingsystem-reduced-exposure-information [Accessed 02 Oct 2021].

55 Lumpkin MM, Bachorik L. FDA goes global. U.S. food and drug administration, 2019. Available: https://www.fda.gov/about-fda/changes-science-law-and-regulatoryauthorities/fda-goes-global [Accessed 16 Nov 2021].

56 University of Bath. PMI Promotion of IQOS Using FDA MRTP Order - TobaccoTactics, 2021. Available: https://tobaccotactics.org/wiki/pmi-iqos-fda-mrtp-order/ [Accessed 02 Oct 2021].

57 Marian C, O'Connor RJ, Djordjevic MV, et al. Reconciling human smoking behavior and machine smoking patterns: implications for understanding smoking behavior and the impact on laboratory studies. Cancer Epidemiol Biomarkers Prev 2009; 18:3305-20.

58 woo KH, young AJ, mi JH. IQOS Store Gwanghwamun Branch "Science Machine, Visually Check the Hazard Difference." Consumuch, 2018. Available: http://www. consumuch.com/news/articleView.html?idxno=41925 [Accessed 01 Oct 2021].

59 jupdding. IQOS science machine experience. 네이버 블로그|그냥 잡다한 이야기, 2018. Available: https://blog.naver.com/j_pudding/221393990401 [Accessed 01 Oct 2021].

60 Tabuchi T. Marketing Strategy for Tobacco Products in Japan. In: Tabuchi T, ed Science and Practice for Heated Tobacco Products: Japan as a Test Bed for Novel Tobacco Products. Springer, 2021: 29-38.

61 Hair EC, Bennett M, Sheen E, et al. Examining perceptions about IQOS heated tobacco product: consumer studies in Japan and Switzerland. Tob Control 2018;27:s70-3.

62 Gravely S, Chung-Hall J, Craig LV, et al. Evaluating the impact of plain packaging among Canadian smokers: findings from the 2018 and 2020 ITC smoking and Vaping surveys. Tob Control 2021. doi:10.1136/tobaccocontrol-2021-056635. [Epub ahead of print: 21 Sep 2021]

63 Staff Writer, Business Tech. South Africa's new cigarette and vaping laws won't do what they say on the packet: tobacco company. Available: https://businesstech.co.za/ news/lifestyle/518788/south-africas-new-cigarette-and-vaping-laws-wont-do-whatthey-say-on-the-packet-tobacco-company/ [Accessed 02 Oct 2021].

64 Nunes-Rubinstein M, Leão T. Arguments used by proponents and opponents in Brazil's regulatory discussions of e-cigarettes and heated tobacco products. Tob Control 2021. doi:10.1136/tobaccocontrol-2021-056628. [Epub ahead of print: 16 Sep 2021].

65 Philip Morris Brasil on Instagram. "Estamos comprometidos em compartilhar os nossos resultados científicos medida que a avaliação dos produtos de risco reduzido avança. A....". Available: https://www.instagram.com/p/CO3Rd02BYEd/?utm_ medium=copy link [Accessed 02 Oct 2021].

66 Vapor Aqui Net on Instagram. "Participe da consulta pública e ajude que milhões de fumantes tenham acesso a produtos que podem salvar suas....". Available: https:// www.instagram.com/tv/CKPo47EgMqR/?igshid=12uu2z2cw6tic [Accessed 02 Oct 2021].

67 Using a smartphone APP with your portable Vape! VapeFuse Blog, 2018. Available: https://blog.vapefuse.com/using-a-smartphone-app-with-your-portable-vape/ [Accessed 01 Oct 2021].

68 Wismec Al. 200W Alexa Compatible Mod w/ Music Player \$55.25 \& Free Shipping (USA). Cheap Vaping Deals, 2020. Available: https://cheapvaping.deals/wismec-ai [Accessed 01 Oct 2021].
69 Wismec ACTIVE 80W Box Mod - Bluetooth Speaker. Available: https://www. elementvape.com/wismec-active-80w-box-mod-bluetooth-speaker [Accessed 01 Oct 2021].

70 Juul to Launch a Bluetooth-Locked Vape to detect Underage smokers in international markets. Available: https://www.newsweek.com/juul-launch-bluetooth-linked-vapedeter-minors-1054773 [Accessed 01 Oct 2021].

71 Dolor R. Juul Launches New Bluetooth-connected E-Cigarette That Tracks User's Vaping. International Business Times, 2019. Available: https://www.ibtimes.com/ juul-launches-new-bluetooth-connected-e-cigarette-tracks-users-vaping-2810849 [Accessed 01 Oct 2021].

72 Equuation D. JUUL 2 Release Date: What Does The Future Hold For JUUL'ers? Available: https://vapebeat.com/vape-news/juul-2-release-date [Accessed 30 Sep 2021].

73 6ixLab. Sticks Today - Connect your iQOS - Apps on Google Play. Available: https:// play.google.com/store/apps/details?id=com.sixlab.today\&hl=en_US\&gl=US [Accessed 02 Oct 2021].

74 Juul launches a Bluetooth e-cigarette that tracks how much you vape - The Verge. Available: https://www.theverge.com/2019/8/6/20754655/juul-c1-bluetooth-ecigarette-vape-monitor-consumption-age-restriction [Accessed 01 Oct 2021].

75 Sarles SE, Hensel EC, Robinson RJ. Surveillance of U.S. corporate filings provides a proactive approach to inform tobacco regulatory research strategy. Int J Environ Res Public Health 2021:18:3067.

76 Kim M, Watkins SL, Koester KA, et al. Unboxed: US young adult tobacco users responses to a new heated tobacco product. Int J Environ Res Public Health 2020;17:E8108

77 Moodie C, Thrasher JF, Cho YJ, et al. Flavour capsule cigarettes continue to experience strong global growth. Tob Control 2019;28:595-6

78 Puff Krush - Pre-filled Add-On Caps. Price Point NY. Available: https://www. pricepointny.com/products/puff-krush-pre-filled-add-on-caps [Accessed 02 Oct 2021]

79 Chaiton MO, Schwartz R, Cohen JE, et al. The use of flavour cards and other additives after a menthol ban in Canada. Tob Control 2021:30:601-2.

80 Facebook. Fruit Flavored Beads For cigarettes. Available: https://www.facebook.com/ medbeet/ [Accessed 02 Oct 2021]

81 Shopee Thailand. Squeeze Beads - Prices and Deals - Oct 2021. Available: https:// shopee.co.th/search?keyword=\%E0\%B9\%80\%E0\%B8\%A1\%E0\%B9\%87\%E0\% B8\%94\%E0\%B8\%9A\%E0\%B8\%B5\%E0\%B8\%9A [Accessed 02 Oct 2021].

82 Facebook. Beads for cigarettes. Available: https://www.facebook.com/Medbitburi/ [Accessed 02 Oct 2021].

83 Leventhal AM, Madden DR, Peraza N, et al. Effect of exposure to e-cigarettes with salt vs Free-Base nicotine on the appeal and sensory experience of Vaping: a randomized clinical trial. JAMA Netw Open 2021:4:e2032757.

84 Jackler RK, Ramamurthi D. Nicotine arms race: JUUL and the high-nicotine product market. Tob Control 2019:28:623-8.

85 Vape Bar. Online Smoke Shop - Wholesale Smoking, Vape and Dispensary Supply. Dream Vape Bar. Available: https://dreamvapebar.com/ [Accessed 02 Oct 2021].

86 Flum Float Disposable Vape 5\% Nicotine 3000 Puffs. Flum Float - Flum Float Disposable Vape 5\% Nicotine 3000 Puffs. Flum Float Disposable Vape Official. Available: https://flumfloat.com/ [Accessed 02 Oct 2021].

87 Robichaud MO, Seidenberg AB, Byron MJ. Tobacco companies introduce 'tobaccofree' nicotine pouches. Tob Control 2020;29:e145-6

88 Hammond D, Reid JL, Burkhalter R, et al. Trends in e-cigarette brands, devices and the nicotine profile of products used by youth in England, Canada and the USA 2017-2019. Tob Control 2021. doi:10.1136/tobaccocontrol-2020-056371. [Epub ahead of print: 07 Jun 2021].

89 Smets J, Baeyens F, Chaumont M, et al. When less is more: Vaping Low-Nicotine vs. High-Nicotine E-Liquid is compensated by increased Wattage and higher liquid consumption. Int J Environ Res Public Health 2019;16:723.

90 Besaratinia A, Tommasi S. The consequential impact of JUUL on youth vaping and the landscape of tobacco products: the state of play in the COVID-19 era. Prev Med Rep 2021;22:101374.

91 Collaborative public health strategies to combat e-cigarette regulation Loopholes | adolescent medicine | JAMA pediatrics | JAMA network. Available: https:// jamanetwork.com/journals/jamapediatrics/fullarticle/2783021 [Accessed 26 Nov 20211.

92 Soneji SS, Sung H-Y, Primack BA, et al. Quantifying population-level health benefits and harms of e-cigarette use in the United States. PLoS One 2018;13:e0193328.

93 Kostygina G, England L, Ling P. New product marketing Blurs the line between nicotine replacement therapy and smokeless tobacco products. Am J Public Health 2016;106:1219-22.

94 Lucy. Lucy - Superior Nicotine Products. Available: https://lucy.co/ [Accessed 02 Oct 2021]

95 RJR Vapor Co. Velo Nicotine Pouches \& Lozenges | No Tobacco Leaf No Limits, 2021. Available: https://https://www.velo.com/home [Accessed 02 Oct 2021]

96 Alushula P. Bat to build Sh2.5bn nicotine pouch plant, 2020Business Daily. Available: https://www. businessdailyafrica.com/bd/corporate/companies/bat-to-build-sh2-5bnnicotine-pouch-plant-2281188 [Accessed 17 Nov 2021]. 
97 British American Tobacco. Modern and traditional oral products. Available: https:// www.bat.com/snus [Accessed 02 Oct 2021].

98 Rogue Holdings LLC. Rogue nicotine on demand | free shipping on nicotine products, 2021. Available: https://www.roguenicotine.com/ [Accessed 02 Oct 2021].

99 Zettler PJ, Hemmerich N, Berman ML. Closing the regulatory gap for synthetic nicotine products. Boston Coll Law Rev 2018;59:1933-82.

100 U.S. Food and Drug Administration. FDA Notifies companies, including Puff Bar, to remove flavored disposable e-cigarettes and youth-appealing e-liquids from market for not having required authorization, 2020. Available: https://www.fda.gov/newsevents/press-announcements/fda-notifies-companies-including-puff-bar-removeflavored-disposable-e-cigarettes-and-youth [Accessed 02 Oct 2021].

101 Truth Initiative. What you need to know about new synthetic nicotine products. Available: https://truthinitiative.org/research-resources/harmful-effects-tobacco/ what-you-need-know-about-new-synthetic-nicotine-products [Accessed 02 Oct 2021].

102 National Association of Attorneys General. Synthetic nicotine in the tobacco and nicotine regulation landscape, 2021. Available: https://www.naag.org/attorneygeneral-journal/determining-synthetic-nicotines-place-in-the-tobacco-and-nicotineregulation-landscape/ [Accessed 30 Sep 2021].

103 Synthetic Nicotine. Next generation Labs TFN®, 2015. Available: https://www. nextgenerationlabs.com/ [Accessed 02 Oct 2021].

104 Tobacco Free Nicotine (TFN): A New Public Health Challenge - Blog - Tobacco Control. Available: https://blogs.bmj.com/tc/2021/07/03/tobacco-free-nicotine-tfn-anew-public-health-challenge/ [Accessed 02 Oct 2021].

105 Zhang H, Pang Y, Luo Y, et al. Enantiomeric composition of nicotine in tobacco leaf, cigarette, smokeless tobacco, and e-liquid by normal phase high-performance liquid chromatography. Chirality 2018;30:923-31.

106 Tobaccolntelligence. Japanese health Ministry denies plan to widen access to tobacco-free pouches, 2021. Available: https://tobaccointelligence.com/japanesehealth-ministry-denies-plan-to-widen-access-to-tobacco-free-pouches/ [Accessed 02 Oct 2021].

107 Peeters S, Gilmore AB. Understanding the emergence of the tobacco industry's use of the term tobacco harm reduction in order to inform public health policy. Tob Control 2015;24:182-9.

108 Magero J. Smokers in Africa: nicotine pouches offer an alternative to "quit or die." Snusforumet, 2021. Available: https://snusforumet.se/en/smokers-in-africa-nicotinepouches-offer-an-alternative-to-quit-or-die/ [Accessed 17 Nov 2021].

109 NIIN LLC. 100\% Tobacco-Free Nicotine Pouches. Available: https://niinpouches.com/ [Accessed 02 Oct 2021]

110 FRE pouch. Buy tobacco-free pouches | tobacco-free nicotine | FRE $\bar{E}$. FRE $\bar{E}$ pouch. Available: https://frepouch.com/ [Accessed 02 Oct 2021].
111 Hendlin YH, Elias J, Ling PM. The Pharmaceuticalization of the tobacco industry. Ann Intern Med 2017;167:278-80.

112 Burki TK. Philip Morris international purchases Vectura. Lancet Respir Med 2021;9:e122.

113 British American Tobacco. Annual reporting. Available: https://www.bat.com/ annualreport [Accessed 02 Oct 2021].

114 Dewhirst T. 'Beyond nicotine' marketing strategies: Big Tobacco diversification into the vaping and cannabis product sectors. Tob Control 2021. [Epub ahead of print: 12 Sep 2021].

115 Hindocha $\mathrm{C}$, Brose LS, Walsh $\mathrm{H}$, et al. Cannabis use and co-use in tobacco smokers and non-smokers: prevalence and associations with mental health in a cross-sectional, nationally representative sample of adults in Great Britain, 2020. Addiction 2021;116:2209-19.

116 Jayakumar N, Chaiton M, Goodwin R, et al. Co-use and mixing tobacco with cannabis among Ontario adults. Nicotine Tob Res 2021;23:171-8.

117 Schauer GL, Berg CJ, Kegler MC, et al. Assessing the overlap between tobacco and marijuana: trends in patterns of co-use of tobacco and marijuana in adults from 2003-2012. Addict Behav 2015;49:26-32.

118 Bastos F, Vasconcellos M, De Boni R. 3rd national survey on drug use by the Brazilian population, 2017.

119 Barry RA, Hiilamo H, Glantz SA. Waiting for the opportune moment: the tobacco industry and marijuana Legalization. Milbank Q 2014;92:207-42.

120 TAAT Global Alternatives Inc. A Nicotine and Tobacco-Free smoking experience. Available: https://taatglobal.com/ [Accessed 02 Oct 2021].

121 Adams D. Best vape 2021 with vape pens and e-cigarettes for the discerning vapeur. T3, 2021. Available: https://www.t3.com/us/features/best-vape [Accessed 02 Oct 2021].

122 CDC's Office on Smoking and Health. Outbreak of lung injury associated with the use of e-cigarette, or Vaping, products. centers for disease control and prevention, 2020. Available: https://www.cdc.gov/tobacco/basic_information/e-cigarettes/ severe-lung-disease.html [Accessed 17 Nov 2021].

123 Now News. One step closer to quitting smoking by improving smoking habits, smoking vitamin "Vitastic." 나우뉴스., 2016. Available: https://nownews.seoul.co. kr/news/newsView.php?id=20160615601013 [Accessed 17 Nov 2021].

124 Leas EC, Moy N, McMenamin SB, et al. Availability and promotion of cannabidiol (CBD) products in online Vape shops. Int J Environ Res Public Health 2021; 18:6719.

125 UK Government. E-Cigarettes could be prescribed on the NHS in world first. GOV. UK, 2021. Available: https://www.gov.uk/government/news/e-cigarettes-could-beprescribed-on-the-nhs-in-world-first [Accessed 17 Nov 2021]. 